\title{
A pegada ecológica à luz da sustentabilidade: o que dizem os estudos recentes?
}

\section{Nicole Stephanie Florentino de Sousa Carvalho ${ }^{1}$, Antônio Jackson Alcântara Frota ${ }^{2}$, Francisco Laercio Pereira Braga $^{3}$ e Gil Célio de Castro Cardoso $^{2}$}

\author{
${ }^{1}$ Universidade Federal do Ceará. Departamento de Economia Agrícola. Av. Mister \\ Hull, 2977, Bloco 826. Campus do Pici. Fortaleza-CE, Brasil (CEP 60020-181). \\ nicolecarvalho01@yahoo.com.br. \\ ${ }^{2}$ Universidade Federal do Ceará. Departamento de Estudos Interdisciplinares. \\ Av. Mister Hull, 2977, Bloco 860. Campus do Pici. Fortaleza-CE, Brasil \\ (CEP 60020-181). \\ ${ }^{3}$ Universidade Estadual do Ceará. Centro de Estudos Sociais Aplicados. Av. Dr. Silas \\ Muguba, 1700. Campus do Itaperi. Fortaleza-CE, Brasil (CEP 60714-110).
}

Resumo. Os indicadores de sustentabilidade surgem como ferramentas ativas importantes para que a sociedade administre devidamente seus sistemas e desenvolva-se de maneira sustentável e, dentre as ferramentas disponíveis, pode-se citar a pegada ecológica. Este artigo objetiva apresentar o indicador de sustentabilidade pegada ecológica dentro da compreensão de ferramenta que viabiliza a visualização das incongruências identificadas na tangência do desenvolvimento sustentável nas sociedades por meio de estudos publicados entre 1990 a 2020. Para atingir este objetivo, trabalhou-se com estudos científicos publicados na literatura internacional e nacional, totalizando 32 trabalhos disponibilizados nas plataformas digitais de pesquisa. A seleção dos estudos publicados refere-se, basicamente, a duas dimensões importantes: i) Indicadores de sustentabilidade; e, ii) Desenvolvimento sustentável. Os resultados observados do conjunto de artigos mostraram, primeiramente, congruência dos autores no que diz respeito aos indicadores de sustentabilidade e sua relevância para a tangência do desenvolvimento sustentável, com destaque para o método da pegada ecológica. Em um segundo momento, o processo analítico dos estudos selecionados deixou evidente a ferramenta de mensuração da pegada ecológica, assim como suas vantagens e desvantagens. Concluiu-se, assim, sobre a importância dada, nos últimos trinta anos, à discussão existente sobre a relação da pegada ecológica com o desenvolvimento sustentável.
Recebido

$13 / 06 / 2021$

Aceito

$27 / 08 / 2021$

Publicado

$31 / 08 / 2021$

Acesso aberto

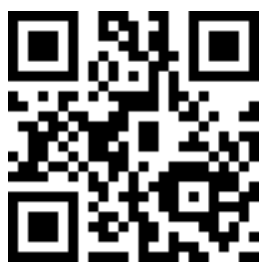

ORCID

(1) 0000-0002-2779-4969

Nicole Stephanie

Florentino de Sousa

Carvalho 
Palavras-chave: Desenvolvimento sustentável; Indicadores de sustentabilidade; Pegada ecológica; Gestão ambiental.

Abstract. The ecological footprint in the light of sustainability: What do the recent studies say? Sustainability indicators emerge as important active tools for society to properly manage its systems and develop in a sustainable manner and, among the available tools, we can mention the ecological footprint. This article aims to present the ecological footprint sustainability indicator within the understanding of a tool that makes it possible to visualize the inconsistencies identified in the tangency of sustainable development in societies through studies published between 1990 to 2020. To achieve this objective, scientific studies published in the international and national literature were worked on, totaling 32 works made available on digital research platforms. The selection of published studies basically refers to two important dimensions: i) Sustainability indicators; and, ii) Sustainable development. The observed results of the set of articles showed, first, the congruence of the authors with regard to sustainability indicators and their relevance to the tangency of sustainable development, with emphasis on the ecological footprint method. In a second step, the analytical process of the selected studies made evident the ecological footprint measurement tool, as well as its advantages and disadvantages. It was concluded, therefore, about the importance given, in the last thirty years, to the existing discussion about the relationship between ecological footprint and sustainable development.

Keywords: Sustainable development; Sustainability indicators; Ecological footprint; Environmental management.
D 0000-0002-1885-4173

Antônio Jackson

Alcântara Frota

(D) 0000-0003-3145-2838

Francisco Laercio

Pereira Braga

(1) 0000-0002-0264-995X

Gil Célio de Castro

Cardoso

\section{Introdução}

A partir do final dos anos de 1960 a percepção global acerca das problemáticas ambientais começava a reverberar entre as nações, onde incidiam fortes críticas a respeito do modo de desenvolvimento dos países industrializados que ainda passavam adiante suas práticas às nações em desenvolvimento. É nesse contexto que as questões em torno do meio ambiente passaram a ser percebidas e demandadas internacionalmente, tendo como prelúdio a criação do Clube de Roma em 1968 (Goes e Morales, 2013). Isso evidencia e traz à tona que as reflexões atuais, diante da valorização da natureza e sua relação com a sociedade, referem-se a um pensar e repensar o desenvolvimento socioeconômico quanto a sua relação complexa entre sociedade e natureza (Morales, 2012).

A partir deste despertar global acerca da desarmonia percebida entre o meio ambiente e as sociedades, várias conferências mundiais começaram a ser encaminhadas a fim de encontrar soluções para as problemáticas evidenciadas. Nesse sentido, a difusão da conceituação de desenvolvimento sustentável no cenário mundial surge em meados dos anos de 1972 a partir do conceito de ecodesenvolvimento, que foi apresentado na Primeira Conferência das Nações Unidas sobre o Meio Ambiente e Desenvolvimento, em Estocolmo, Suécia. A definição do termo realizou-se no Relatório Brundtland (1987) como resultado da Comissão Mundial sobre o Meio Ambiente e o Desenvolvimento em 1987. A consolidação e institucionalização acerca da sustentabilidade ocorrem no ano de 1992, 
estabelecida dentro da Segunda Conferência das Nações Unidas sobre Meio Ambiente e Desenvolvimento (Rio-92 ou Eco-92).

Este itinerário, que parte dessas premissas estabelecidas no contexto mundial, trouxe à tona o reconhecimento e a relevância de projetar meios e modos de agir que levem ao desenvolvimento social e econômico, mantendo uma interação harmônica com o meio ambiente e a utilização dos recursos naturais. Dessa forma, o desenvolvimento sustentável busca ser instrumento de agregação para uma elevação da qualidade de vida das nações, em observância também aos insumos que estão disponíveis no planeta. As práticas de consumo e demais hábitos de comportamento são paulatinamente reinventados, de modo a inserir novas perspectivas que levarão ao desenvolvimento socioeconômico em correspondência às questões ambientais, bem como culturais e éticas.

Para correlacionar de maneira eficiente meio ambiente, desenvolvimento e sociedade, é necessário desenvolver mecanismos de mensuração e avaliação dos níveis de sustentabilidade. Assim, com um auxílio de um indicador, é factível compilar dados e informações, permitindo que fenômenos possam ser quantificáveis e melhor compreendidos. Dessa maneira, é possibilitada a tomada de decisões no contexto da gestão dos sistemas (econômicos, sociais, institucionais, ambientais e políticos) com maior presteza e abrangência, direcionando também para, a partir dos dados obtidos, sedimentar metas que tangenciem o alcance do desenvolvimento sustentável.

Diante deste panorama, os indicadores de sustentabilidade são ferramentas importantes para que uma sociedade possa administrar devidamente seus sistemas e, com isso, desenvolver-se de maneira sustentável. Vale ressaltar que existem diferentes formas de operacionaliza-los, concebendo diversificados mecanismos de mensuração. Dentre as diversas ferramentas que podem ser utilizadas com essa finalidade, tem-se a pegada ecológica, que é um instrumento de grande eficiência e que pode ser observado nesse conjunto, pois sua estimação é um importante parâmetro na condução do desenvolvimento sustentável, servindo como um termômetro dos impactos dos hábitos e modo de vida de uma população quanto ao ecossistema (Santos et al., 2018). Além disso, a clareza na transparência de seus resultados direciona a um encaminhamento efetivo para a solução dos problemas encontrados (Dias, 2015).

Este contexto deixa evidente a notória importância evidenciada na articulação e despertar mundial orientados, desde o final dos anos de 1960, acerca da problemática ambiental que começava a se tornar insurgente. No entanto, a partir do uso de indicador de sustentabilidade, em muitos casos, pode ser verificado um alargado distanciamento entre os discursos bem intencionados e a práxis efetiva. Isso direciona a ação das nações para o alcance do desenvolvimento sustentável em circunstancias diversas, o que pode ser pouco eficiente quando almejados os reais interesses coletivos e ambientais. Nesse aspecto, a pergunta norteadora desta pesquisa é, qual a compreensão existente na literatura sobre o indicador de sustentabilidade pegada ecológica como ferramenta de visualização de incongruências do desenvolvimento sustentável nas sociedades?

Em vista disso, este artigo objetiva apresentar o indicador de sustentabilidade Pegada Ecológica dentro da compreensão de ferramenta que viabiliza a visualização das incongruências identificadas na tangência do desenvolvimento sustentável nas sociedades por meio de estudos publicizados entre os anos de 1990 a 2020.

\section{Materiais e métodos}

Para atingir o objetivo proposto neste artigo, trabalhou-se com artigos científicos publicados entre os anos de 1990 a 2020 na literatura internacional e nacional, totalizando, ao final, 32 trabalhos disponibilizados nas plataformas digitais de pesquisa. 0 levantamento procedeu do exame sobre os mais expressivos normativos de língua portuguesa, inglesa e espanhola a abordar as categorias de análise do problema em 
estudo. Utilizou-se da coleta de artigos e demais trabalhos acadêmicos em periódicos com relevância científica classificados entre os estratos A1, A2, B1, B2 e B3 do Qualis Capes. Também foram utilizados trabalhos de conclusão de curso, dissertações de mestrado e teses de doutorado, além de sites oficiais de informação e ONGs, como o Global Footprint Network e o WWF Brasil, e outros.

As principais plataformas que foram utilizadas para coleta do material em estudo foram Google Scholar, Scientific Electronic Library Online (SciELO), Red de Revistas Científicas de América Latina y el Caribe, España y Portugal (Redalyc), Science Direct e repositórios acadêmicos online de universidades brasileiras.

A seleção desse conjunto de estudos publicados abrangem, basicamente, a duas dimensões importantes da temática em questão, i) indicadores de sustentabilidade, o qual inclui o método da pegada ecológica com suas vantagens e desvantagens; e ii) desenvolvimento sustentável, que se relaciona diretamente com a utilização do método da pegada ecológica (Figura 1).

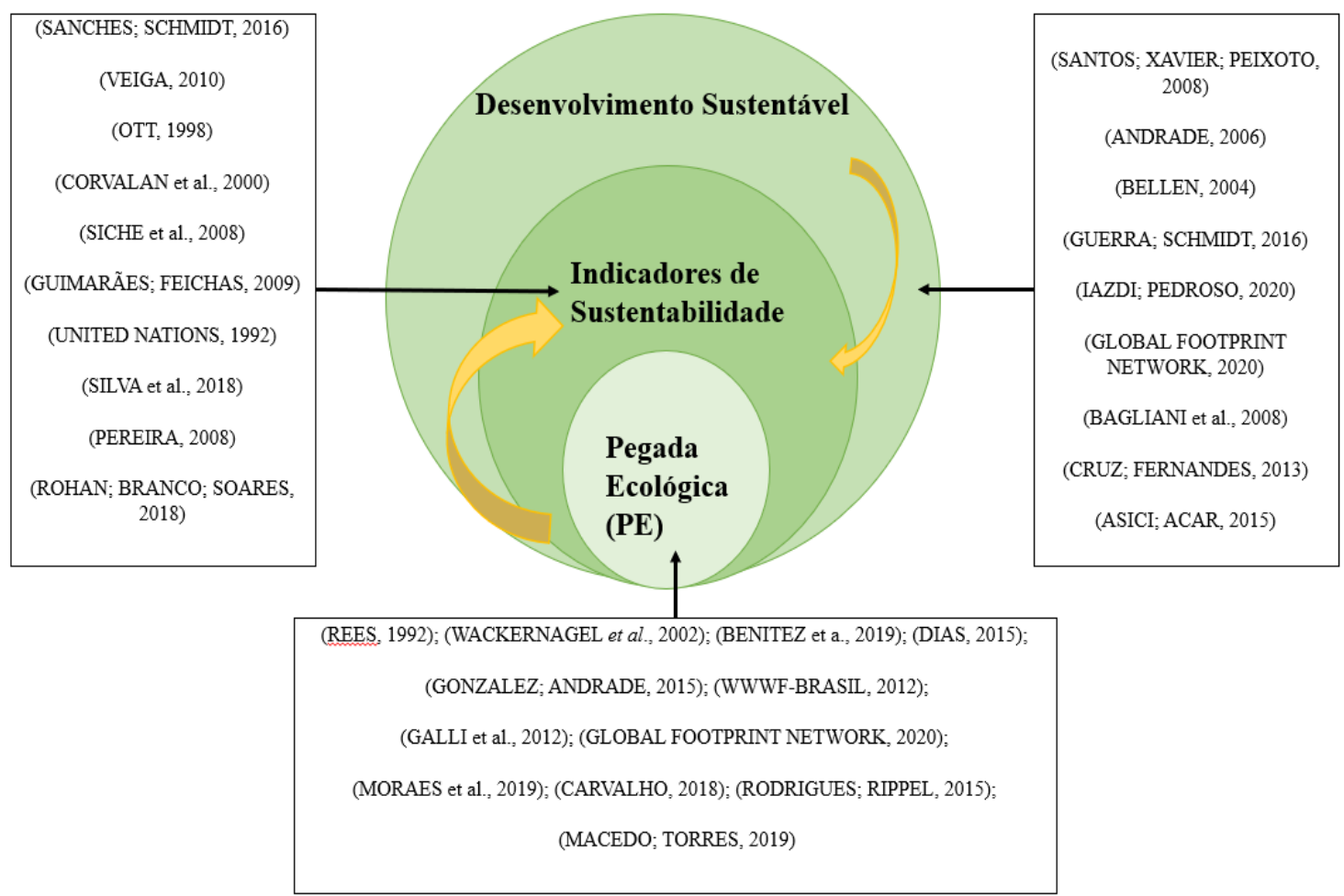

Figura 1. Desenho metodológico da pesquisa bibliográfica.

\section{Resultados e discussão}

\section{Indicadores de sustentabilidade}

De acordo com Sanches e Schmidt (2016), um indicador facilita a compilação de dados e informações, possibilitando que fenômenos possam ser quantificáveis e melhor compreendidos. Isso permite a tomadas de decisões no âmbito da gestão dos sistemas econômicos, sociais, institucionais e ambientais, com maior clareza e abrangência, 
direcionando também para, a partir dos dados obtidos, sedimentar metas que tangenciem o alcance do desenvolvimento sustentável.

As premissas a respeito da compreensão sobre os indicadores de sustentabilidade começaram a ser estabelecidas no início dos anos de 1970. Segundo Veiga (2010), as discussões científicas sobre os indicadores de sustentabilidade reverberaram a partir de Nordhaus e Tobin (1972), que não tinha o foco de tratar especificamente dos indicadores de sustentabilidade, mas levantar pontos hipotéticos sobre a obsolescência do crescimento econômico.

Veiga (2010) deixa claro, portanto, que Nordhaus e Tobin (1972) trataram sobre a consistência das medidas utilizadas para avaliar o crescimento econômico. Deve-se mencionar, portanto, que esta reflexão tornou-se a primeira referência base para a compreensão posterior a respeito dos indicadores de sustentabilidade. Isso porque, uma vez que foi refutada a eficiência de mensuração dos índices de contabilidade nacional, como o Produto Interno Bruto (PIB) ou Produto Nacional Bruto (PNB), para a abrangência do bem-estar socioeconômico, os especialistas realizaram correções no método de cálculo dos agregados macroeconômicos, retirando variáveis que não contribuíam para o bemestar e acrescentando outras que não entravam no cálculo convencional por não fazerem parte da produção. Dessa forma, construiu-se a "Medida de Bem-estar Econômico", o qual introduzia uma variável que abordava o nível de sustentabilidade, emergindo o primeiro estudo a utilizar-se de um indicador com essa finalidade (Veiga, 2010).

As premissas desenvolvidas sobre o primeiro estudo que trouxe à tona a concepção a respeito dos indicadores de sustentabilidade foram sendo sedimentadas no transpor das últimas décadas. A elaboração e aplicação dos indicadores como ferramenta de mensuração e meio de interpretação e avaliação de uma realidade foi trabalhada por vários autores (Ott, 1998; Corvalan et al., 2000; Bellen, 2006; Siche et al., 2007; Guimarães e Feichas, 2009), e partem da importância do conhecimento e da definição precisa do que se deseja medir. Além disso, ressaltam a necessidade da correspondência do meio eficiente da coleta de informações com a adequação à tomada de decisão nos diferentes contextos políticos encontrados para a solução dos problemas.

0 reconhecimento e estabelecimento dos indicadores de sustentabilidade evidenciou-se com notoriedade e consistência a partir da conferência Eco-92, em que foi expressa, internacionalmente, a necessidade de desenvolver indicadores de avaliação para a sustentabilidade. No Capítulo 40,da Agenda 21, este fato é institucionalizado:

\footnotetext{
Os indicadores comumente utilizados, como o produto nacional bruto (PNB) ou as medições das correntes individuais de contaminação ou de recursos, não dão indicações precisas de sustentabilidade. Os métodos de avaliação da interação entre diversos parâmetros setoriais do meio ambiente e o desenvolvimento são imperfeitos ou se aplicam deficientemente. É preciso elaborar indicadores de desenvolvimento sustentável que sirvam de base sólida para adotar decisões em todos os níveis, e que contribuam a uma sustentabilidade autorregulada dos sistemas integrados do meio ambiente e o desenvolvimento" (United Nations, 1992, p. 465-466).
}

Siche et al. (2008) ressaltam que a proposta fomentada pela conferência Eco-92 orientava para a necessidade de sistematização de indicadores que mensurassem e avaliassem os níveis de sustentabilidade em observância aos sistemas econômicos, sociais, ambientais, culturais e éticos. Dessa maneira, visto a complexidade envolta aos sistemas que integram o meio ambiente, as dimensões econômicas, sociais e institucionais do desenvolvimento sustentável (Silva et al., 2018), os indicadores de sustentabilidade são parâmetros úteis e necessários para levar a reflexão e a articulação de ações políticas e de gestão pública e privada. 
Segundo Pereira (2008), os indicadores desempenham três importantes funções para as avaliações de sustentabilidade, dentre elas: auxiliar na pormenorização das disposições de sistemas complexos e independentes. Em muitos casos, a mensuração dos indicadores pode facilitar avaliação de desempenho para conduzir a implementação de políticas públicas que visem à sustentabilidade, servindo de alerta para mudanças nos sistemas ambientais, sociais, culturais e econômicos. É muito importante ressaltar a relação dos indicadores com os sistemas para a descrição de todas as circunstâncias de seu desempenho, pois é uma medida da eficiência das ações que objetivam a sustentabilidade. Ainda segundo Pereira (2008), para o entendimento e administração dos sistemas é preciso uma forma de mensurar seu desempenho, o que se fundamenta na importância dos indicadores de sustentabilidade como mecanismo para que uma sociedade possa administrar devidamente seus sistemas e desenvolver-se de maneira sustentável.

O Ecological Footprint Method (Método da Pegada Ecológica) é o indicador de sustentabilidade com maior reconhecimento internacional de acordo com Bellen (2004b). Segundo Rohan et al. (2018), quando perscrutada somente a dimensão ambiental dos sistemas, essa ferramenta de mensuração possui a maior eficiência de alcance ao ser comparada com outros métodos de aferição da sustentabilidade. Assim, a pegada ecológica revela grande potencialidade no que diz respeito à tangência de reflexões e tomada de decisões no âmbito das políticas ambientais e demais categorias que perscrutem o meio ambiente. Na próxima seção este importante mecanismo será aprofundado.

\section{Pegada ecológica}

Diante da literatura acadêmica sobre o Ecological Footprint Method, tem-se um estudo de indiscutível destaque no que diz respeito aos indicadores de sustentabilidade que foi o realizado por Rees (1992) e Wackernagel e Rees (1996), que dispõem a pegada ecológica ou ecological footprint como ferramenta de análise e mensuração dos índices de desenvolvimento sustentável. Benitez et al. (2019) ressaltam, por sua vez, que a pegada ecológica é um indicador biofísico que avalia a sustentabilidade correlata a um grupo de impactos exercidos por uma comunidade humana específica (cidade, ou região) ao meio natural que está inserida. Essa perspectiva fomenta que o cálculo disposto pela Pegada Ecológica é um importante recurso que identifica e leva a determinação dos níveis de sustentabilidade (Dias, 2015).

Neste contexto, o mecanismo também se torna um indicador de grande pertinência para a educação ambiental, dado que o conhecimento a respeito das condições de sustentabilidade de um determinado ambiente pode direcionar reflexões importantes entre meio natural face o social e o econômico. Quando esses dados são orientados por especialistas podem levar a um resultado relevante quanto ao direcionamento de mudanças comportamentais, de ações e de políticas. Isso ocorre na medida em que podem ser gerados índices que relacionem a sociedade com o meio ambiente quanto à intensidade do efeito de suas escolhas sob os sistemas ambientais (Guimarães e Feichas, 2009).

Pereira (2008) expressa que o ponto central para a ordenação do método da pegada ecológica é tangenciado pela realização das atividades humanas e suas habilidades ao provimento dos serviços e demandas de consumo. Assim, o efeito das ações do homem na natureza relaciona-se diretamente com a integridade dos ecossistemas, tornando necessária a observância de seus impactos. Gonzalez e Andrade (2015) enfatizam que dentre os diferentes métodos existentes para o diagnóstico da situação ambiental de determinada área, a pegada ecológica destaca-se pelo fato de seus resultados serem apresentados de maneira muito intuitiva, o que direciona sua difusão.

Gonzalez e Andrade (2015) sintetizam que de maneira simplificada, a pegada ecológica apresenta se o consumo da população de uma dada área pode ser comportado 
por ela, ou seja, se possuem recursos suficientes nesta área para a produção de bens e serviços que naquele ambiente são consumidos. Assim, para a determinação de sua magnitude é necessário conhecer: o tamanho da população; o grau de intensidade da utilização dos recursos na produção de bens e serviços (eficiência energética e material); e a magnitude do consumo de bens e serviços per capita que, por sua vez, está em função na renda disponível.

Então, pode-se dizer que o indicador de sustentabilidade pegada ecológica é uma metodologia de aferição que consiste em acompanhar as demandas dos seres humanos sobre a biosfera, realizando a comparação de suas devidas capacidades (WWF Brasil, 2012). Nessa perspectiva, com intuito de verificar as demandas humanas direta e indireta dissipadas em suas atividades e serviços, também no que diz respeito à produção de recursos renováveis e assimilação de dióxido de carbono $\left(\mathrm{CO}_{2}\right)$, pegada de carbono (Galli et al., 2012), são realizados cálculos para mensurar o quanto da capacidade regenerativa dos ecossistemas é impactada com o modo de vida humano.

\section{Metodologia de cálculo da pegada ecológica}

Para que a ferramenta Pegada Ecológica possa ser operacionalizada, Wackernagel et al. (2002) propõem a compreensão de 6 pressupostos fundamentais, são eles:

- Quase todos os recursos que são consumidos pelos indivíduos e os resíduos gerados podem ser mapeados e quantificados;

- um subconjunto relevante dos fluxos de recursos e resíduos pode ser calculado em termos de área biologicamente produtiva necessária para o mantimento destes fluxos. Fluxos de recursos e resíduos que não podem ser aferidos são excluídos da avaliação, levando, dessa maneira, a uma subestimação sistemática de uma verídica Pegada Ecológica da humanidade;

- ao ponderar cada área em proporção à sua bioprodutividade, distintas áreas podem ser transformadas em uma unidade comum de hectares globais - hectares com a bioprodutividade média mundial;

- dado que um único hectare global representa um único uso, e cada hectare global em um determinado ano corresponde a mesma quantidade de bioprodutividade, elas podem ser adicionadas para a obtenção de um indicador agregado da Pegada Ecológica ou biocapacidade;

- a demanda humana, apresentada como Pegada Ecológica, pode ser diretamente comparada a biocapacidade, quando ambas são apresentadas em hectares globais;

- a área demandada pode exceder a área ofertada se a demanda em um ecossistema ultrapassa a capacidade regenerativa deste ecossistema.

Os pressupostos apresentados derrogam, portanto, que o impacto ecológico da humanidade é mensurado como a área de terra e água biologicamente produtiva necessária para produção dos recursos consumidos e a devida assimilação dos resíduos gerados pela humanidade em um determinado período. No entanto, não apenas a demanda humana pela natureza, mas, também, a oferta da natureza se altera ao longo do tempo devido às inovações tecnológicas e as modificações no gerenciamento de recursos, devendo considerar, ainda, as mudanças no uso da terra e as mazelas acumuladas de impactos passados (Wackernagel et al., 2002).

Nesta perspectiva, o cálculo da Pegada Ecológica parte da concepção de que para cada item de matéria ou energia utilizada pela população, existe uma área de terra necessária para proporcionar os recursos que são precisos de matéria e energia para comportar os resíduos que forem gerados. Para que se possa delinear a área total requerida capaz de suportar certo padrão de consumo, as implicações do uso da terra devem ser estimadas. Contudo, considera-se a impossibilidade de mensurar a demanda 
por área produtiva para manutenção, disposição e provisão dos diversos bens de consumo, pois os cálculos se limitam às categorias mais importantes de bens e a alguns itens individuais (Bellen, 2006).

Em decorrência disto, de acordo com Bellen (2006), o mecanismo para avaliação da área de um ecossistema, ou ambiente ecológico, necessário para a garantia da sobrevivência dessa população deve proceder a partir da sequência dos pontos:

- Realizar o cálculo da média anual do consumo de itens particulares dos dados agregados, nacionais ou regionais, partindo da divisão do consumo total pelo tamanho da população (consumo anual per capita);

- determinar o cálculo ou a estimativa da área apropriada per capita para a produção individual dos principais itens de consumo, realizando-se a divisão do consumo anual per capita (kg/capita) pela produtividade média ao ano (kg/ha);

- calcular a área obtida pela Pegada Ecológica média por pessoa, por meio do somatório das áreas apropriadas per capita, por item de consumo de bens ou serviços, os quais foram aferidos no ponto anterior;

- mensurar a área da Pegada Ecológica total, determinada pela multiplicação da área da Pegada Ecológica média, por pessoa, pelo tamanho da população total.

Desta forma, a pegada ecológica é representada pela área biologicamente produtiva que seria necessária para o abastecimento dos recursos naturais utilizados e para a destinação dos rejeitos (Veiga, 2010). Grande parte das estimativas existentes referentes ao método é baseada em médias de consumo nacional e de produtividade global da terra. Essa padronização é importante para a efetuação e facilitação dos estudos de caso e comparações entre regiões e países. Nesse sentido, a pegada ecológica possui hábil e ampla utilização para estudos e pesquisas que têm a finalidade de avaliação dos impactos ambientais.

Um mecanismo simplificado para o conhecimento, realização e comparação de cálculos da pegada ecológica em todo globo pode ser possibilitado por meio das ferramentas disponíveis em Global Footprint Network (2020). Trata-se de uma organização internacional sem fins lucrativos criada em 2003, que apresenta históricos atualizados de dados robustos referentes à pegada ecológica e à biocapacidade em diferentes contextos regionais em todo o mundo. Além disso, fornece a possibilidade de aferição da pegada ecológica individual e institucional a partir de uma calculadora online.

\section{Principais vantagens e desvantagens do método}

A ferramenta pegada ecológica, assim como todo método científico, possui vantagens e desvantagens que deflagram de sua utilização. No que tange aos seus benefícios, Moraes et al. (2019) enfatizam que por se tratar de um mecanismo sintético de desempenho ecológico, favorece o desenvolvimento de estratégias pautadas na produtividade mundial. Além disso, quando se trata de uma população específica, a ferramenta sinaliza a área necessária para que se mantenha indefinidamente.

Outra vantagem que perscruta da utilização do método se refere à possibilidade da criação de mecanismos propícios para a gestão e educação ambiental. Carvalho (2018) ao mensurar a pegada ecológica no contexto de uma universidade, evidenciou os efeitos positivos que o conhecimento dos níveis de sustentabilidade da Instituição de Ensino Superior possibilitou. Segundo aquele estudo, a percepção desses resultados direcionou para uma autocrítica ao comportamento institucional acadêmico na tangência da sustentabilidade, levando a universidade a repensar seus padrões de consumo e gerenciamento, agregando atividades extensionistas para esta finalidade. 
Corroborando, Rodrigues e Rippel (2015) ressaltam que a pegada ecológica é um método tanto analítico quanto educacional, porque se direciona a possibilidade de compreender a sustentabilidade por meio das atividades realizadas pelos homens, fornecendo elementos para, a partir daí, galgar e sedimentar a consciência ambiental nos diferentes contextos. Rodrigues e Rippel (2015) ainda acrescentam que a ferramenta auxilia na tomada de decisão, tornando mais robusta a visão de sistema integrado, ou seja, fortalecendo a relação de dependência existente entre a sociedade e o ecossistema.

A respeito das desvantagens, Macêdo e Torres (2019) apresentam o fato de não ser considerada a dinamicidade que é inerente aos sistemas, além disso, somente são levadas em consideração as questões econômicas das decisões que partem da utilização dos recursos. Isso se explica porque a pegada ecológica direciona-se ao escopo da avaliação do desenvolvimento sustentável somente no que refere a sua dimensão ecológica. 0 que, certamente, caracteriza uma limitação para o método, dado que não são abarcadas pela ferramenta todas as outras demais dimensões que são inerentes ao desenvolvimento sustentável - social, institucional e econômica (Rodrigues e Rippel, 2015).

Ademais, também é apontado como ponto negativo, o fato de se tratar de um indicador praticamente estático, ou seja, apenas o estado atual é demonstrado sem realizar extrapolações, o que para um indicador é visto como uma limitação. Isto é evidenciado pelos próprios criadores da ferramenta (Wackernagel e Rees, 1996) que fazem uma autocrítica ao afirmarem que o método apresenta apenas uma simplificação da realidade (Moraes et al., 2019).

\section{A Pegada ecológica e o desenvolvimento sustentável}

Santos, et al. (2008) enfatizam a simplicidade do entendimento da pegada ecológica como ferramenta de medição do desenvolvimento sustentável. Segundo Santos, et al. (2008), possibilita-se com o método realizar comparações entre regiões e sociedades, tendo como objetivo principal a evidenciação dos limites do crescimento, atentadas às questões ambientais. Nessa perspectiva, a proposta central de aplicação do método da pegada ecológica é articulada objetivando a condução de decisões e a motivação para o encaminhamento da consciência pública sobre os problemas ambientais.

Neste sentido, o instrumento de sustentabilidade tem a ambição de corroborar a uma percepção abrangente envolta da problemática ambiental, pois: "A Pegada Ecológica permite uma análise das causas imediatas dos problemas e suas prováveis tendências de evolução" (Andrade, 2006, p. 19). Esse método evidencia, portanto, seu importante papel na identificação das principais transgressões da relação do ser humano com o ambiente.

Para Bellen (2004a), a pegada ecológica provocaria uma reflexão importante à realidade biofísica. Com o método é possível visualizar a finitude advinda da natureza, levando a consciência do limite ao crescimento econômico, caso contrário, pode ser gestada a destruição das espécies. Dessa forma, trata-se de um instrumento de sustentabilidade que instiga a percepção dos atuais desafios enfrentados pela sociedade, ao trazer isso à tona no objetivo de conquistar modelos sociais mais sustentáveis. Num entendimento de causa e efeito, envoltas nas restrições da natureza e nos interesses e ações humanas, leva à compreensão da correlação entre pegada ecológica e desenvolvimento sustentável, e o seu papel desafiador em torno da realidade observada.

Essa perspectiva desafiadora se evidencia e é aprofundada por Guerra e Schmidt (2016), que apresentam uma crítica contundente a respeito da ambiguidade enraizada no contexto global quando perscrutada a consciência mundial referente aos reais reflexos do desenvolvimento sustentável. Guerra e Schmidt (2016) demonstram as contradições dos sistemas por meio dos dados de mensuração da pegada ecológica global entre os anos de 1961 e 2011 (Figura 2). 


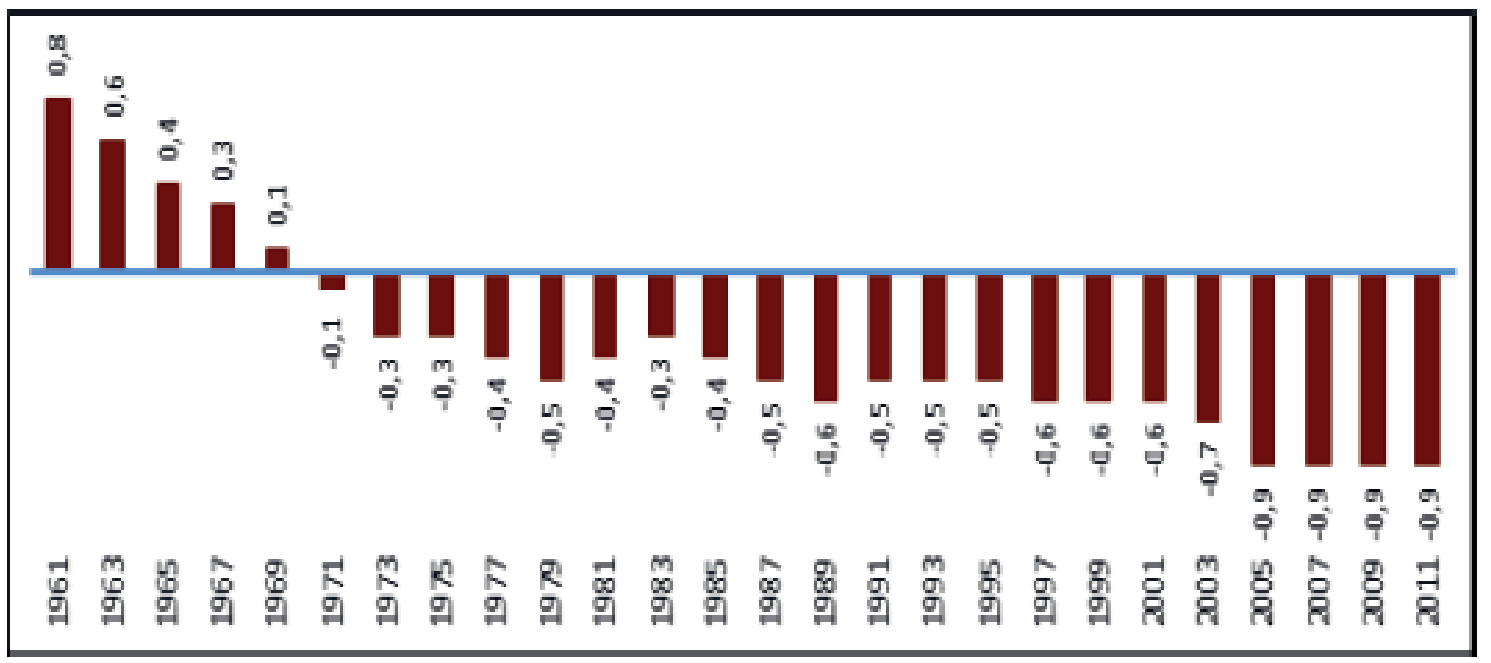

Figura 2. Evolução do déficit ecológico mundial per capita (1961-2011). Fonte: Global Footprint Network (2015).

A Figura 2 mostra que a crescente disparidade entre a pegada ecológica global, que aumenta a cada ano, e a biocapacidade do planeta, que é reduzida a cada ano, desde o início da década de 1970, é largamente acentuada. A averiguação desse fato denuncia que mesmo com as várias conferências globais patrocinadas pela ONU, após o alerta deixado no Clube de Roma; dos vários documentos e agendas decorridos dos encontros globais; e mesmo com avanços pontuais, como a redução da pobreza extrema em algumas nações, a disseminação da preocupação e conscientização ambiental e dos limitados vestígios de recuperação da qualidade ambiental; de certo modo imbuídos nos contextos de maior afluência econômica, os resultados do esperado desenvolvimento sustentável demonstram-se frágeis e inconsistentes (Guerra e Schmidt, 2016).

A relação da pegada ecológica com o desenvolvimento sustentável, nesse sentido, está para além de ser um indicador eficiente dos níveis de sustentabilidade que podem ser mensurados em determinada área ou região. Isso porque o uso da ferramenta permite inúmeras reflexões que envolvem os sistemas de crescimento e desenvolvimento econômico no âmbito das sociedades, denunciando sua incongruência com os limites dos ecossistemas, e mostrando que pouco se contribuiu para reverter as crises ambientais. Pelo contrário, na verdade constatou-se seu aprofundamento.

Esse pensamento pode ser ratificado ao também relacionar o indicador com o crescimento econômico. Isso ocorre, pois, ao perscrutar a variável Produto Interno Bruto (PIB) per capita com a biocapacidade per capita, correlacionando-os com dados referentes à pegada ecológica per capita, é possibilitado vislumbrar como os níveis de crescimento econômico e de desenvolvimento sustentável se relacionam, sendo instrumento de ponderação a respeito das contradições dos sistemas. Iazdi e Pedroso (2020) apresentaram reflexões importantes a partir dessa relação no âmbito da América do Sul.

Iazdi e Pedroso (2020) realizaram um estudo que teve por método a análise estatística de correlação entre o PIB per capita (PIB_PC), a pegada ecológica per capita (PE_PC) e a biocapacidade per capita (BC_PC) para oito países pertencentes à América do Sul (Argentina, Bolívia, Brasil, Chile, Colômbia, Paraguai, Peru e Venezuela). 0 período analisado no estudo compreendeu os anos de 1961 a 2016, utilizando-se de dados do Global Footprint Network (2020). 
Para o estudo, Iazdi e Pedroso (2020) partiram do cálculo de coeficiente de correlação de Pearson, realizando, em seguida, uma Análise de Componentes Principais (PCA), que se baseia na própria correlação de dados, intuindo qualificar e validar os resultados encontrados a partir de sua variabilidade. Assim, utilizando-se das variáveis PIB_PC, PE_PC e BC_PC para alguns países selecionados da América do Sul, os autores verificaram como a pegada ecológica contribui para discussão sobre o desenvolvimento sustentável, sobretudo, evidenciando o possível antagonismo entre o crescimento econômico e o meio ambiente (Tabela 1).

Tabela 1. Matriz de correlação.

\begin{tabular}{|l|c|c|c|}
\hline Países & PIB_PC versus BC_PC & PIB_PC versus PE_PC & p-Value (médio) \\
\hline Argentina & $-65,32 \%$ & $-4,22 \%$ & 0,0030 \\
\hline Bolívia & $-76,09 \%$ & $90,28 \%$ & 0,0010 \\
\hline Brasil & $-95,48 \%$ & $82,63 \%$ & 0,0005 \\
\hline Chile & $-80,24 \%$ & $92,62 \%$ & 0,0000 \\
\hline Colômbia & $-90,96 \%$ & $-67,20 \%$ & 0,0000 \\
\hline Paraguai & $-95,06 \%$ & $12,96 \%$ & 0,0000 \\
\hline Peru & $-45,83 \%$ & $18,18 \%$ & 0,0007 \\
\hline Venezuela & $23,47 \%$ & $11,28 \%$ & 0,0000 \\
\hline
\end{tabular}

Fonte: Iazdi e Pedroso (2020).

Os dados da Tabela 1 apresentam a evidência de uma forte correlação negativa que ocorre entre o PIB per capita e a biocapacidade per capita. Além disso, retratam uma correlação positiva entre o PIB per capita e a pegada ecológica per capita. Isso traz à tona a existência de uma correlação clara entre o crescimento econômico e o esgotamento do capital natural, o que é refletido tanto pelos grandes níveis de consumo verificados através da pegada ecológica, como pela biocapacidade territorial, que, conforme constatado pelo estudo, caminha em sentido contrário à evolução do PIB dos países sul americanos (Iazdi e Pedroso, 2020).

As evidências apresentadas por Guerra e Schmidt (2016) e Iazdi e Pedroso (2020), somam-se a outros compêndios que fortalecem através de diversas pesquisas empíricas, a relação do indicador de sustentabilidade pegada ecológica como ferramenta viabilizadora das incongruências na tangência do desenvolvimento sustentável nas sociedades. Autores como Bagliani et al. (2008), Cruz e Fernandes (2013) e Asici e Acar (2015), apresentam que a pegada ecológica ao relacionar-se com o crescimento econômico de diversas nações, revela que quando maior o PIB de um país, mais elevada é sua a pegada ecológica e, consequentemente, o seu impacto ambiental.

Este fato traz reflexões contundentes, dado que tanto países em desenvolvimento, conforme apresentado por Iazdi e Pedroso (2020), como as nações desenvolvidas, desde o despertar mundial para a problemática ambiental no final dos anos de 1960, apresentam um crescente distanciamento de um desenvolvimento tido como sustentável, demonstrando aprofundamento das mazelas ambientais. Tudo isso ratifica o pensamento de Bellen (2004a), que ressalta a relevância do uso da pegada ecológica para a reflexão dos limites para o crescimento econômico e da sobrecarga relativa ao uso dos recursos naturais. 


\section{Considerações finais}

Este estudo teve como pano de fundo a percepção das nações mundiais sobre as problemáticas ambientais a partir de 1960, momento que iniciaram críticas a respeito do modo de desenvolvimento adotado pelos países industrializados e que foi disseminado para as nações em desenvolvimento. Esse movimento insurgente trouxe debates, aprofundamento de estudos e reflexões que perduram até os dias atuais, com o foco principal na valorização da natureza e sua relação com a sociedade. Esse cenário propiciou o reconhecimento sobre a importância da necessidade de existência da harmonização entre meio ambiente, utilização de recursos naturais e desenvolvimento socioeconômico. Assim, para uma adequada correlação entre esses elementos, faz-se necessário a elaboração e desenvolvimento das ferramentas de mensuração e avaliação dos níveis de sustentabilidade da sociedade de forma a possibilitar a administração de seus sistemas, tais como a pegada ecológica.

Desta maneira, este artigo conseguiu alcançar seu objetivo geral ao apresentar o indicador de sustentabilidade Pegada Ecológica dentro da compreensão de ferramenta que viabiliza a visualização das incongruências identificadas na tangência do desenvolvimento sustentável nas sociedades, o que somente foi possível por meio do estudo analítico dos estudos publicizados entre os anos de 1990 a 2020 na literatura internacional e nacional.

Os estudos analisados apontaram a importância da elaboração e utilização de indicadores para facilitar o conhecimento e a quantificação de fenômenos, principalmente aqueles relacionados à temática do crescimento econômico. Dentre os grupos de indicadores apontados têm-se aqueles referentes à sustentabilidade, que ganharam notoriedade nos debates e discussões acadêmicas e de formulação de políticas públicas e privadas. Dessa maneira, tais indicadores tornaram-se mecanismos relevantes para serem utilizados pelas sociedades como forma de administrar seus sistemas e desenvolver-se sustentavelmente.

Neste contexto, os estudos pioneiros sobre a questão do desenvolvimento sustentável e seus indicadores apontam o Método Ecological Footprint ou Pegada Ecológica como ferramenta/instrumento de grande importância para análise e mensuração dos índices de desenvolvimento sustentável, além de ser objeto de educação ambiental, pois possibilita reflexões sobre meio natural face o social e o econômico. Esses estudos revelaram, também, o potencial existente da pegada ecológica no que diz respeito às reflexões e ao processo de tomada de decisão, principalmente no âmbito das políticas ambientais. Por esse motivo, o método pegada ecológica é de ampla utilização em estudos e pesquisas que envolvem avaliação dos impactos ambientais.

Este trabalho conseguiu, ainda, por meio da análise bibliográfica, identificar as principais vantagens e desvantagens do método pegada ecológica. Dentre as vantagens apontadas na literatura, pode-se mencionar: a) favorece o desenvolvimento de estratégias pautadas na produtividade mundial (dado seu caráter sintético de desempenho ecológico); b) auxilia na definição de áreas necessárias para que se mantenham indefinidamente; c) possibilita a criação de mecanismos propícios para a gestão e educação ambiental; d) direciona a compreensão da sustentabilidade por meio das atividades realizadas pelos homens, o que sedimenta a consciência ambiental; e, e) ajuda na tomada de decisão ao fortalecer a relação de dependência entre a sociedade e o ecossistema. No que diz respeito às desvantagens, os autores selecionados mencionam dois fatores que se caracterizam como negativos do método pegada ecológica, o primeiro deles é não considerar a dinamicidade, que é inerente aos sistemas, pois levam em consideração questões que envolvem a dimensão econômica. Em segundo, por se tratar de 
um indicador estático, leva-se em consideração apenas o estado atual sem a realização de extrapolações, o que é um fator limitante quando se trabalha com indicadores.

Por último, a pesquisa conseguiu, no seu escopo, relacionar o método pegada ecológica com a questão do desenvolvimento sustentável, onde os estudos apontaram que o método possibilita comparações entre regiões e sociedades, cujo objetivo seja a evidenciação dos limites do crescimento atentas às questões ambientais. 0 método possui importante papel na identificação das principais transgressões da relação do ser humano com o ambiente, em que é possível visualizar a finitude advinda da natureza, assim como a consciência do limite ao crescimento econômico. Dessa maneira, o método instiga a percepção e reflexão dos desafios enfrentados pela sociedade quando se tem o objetivo de conquistar modelos sociais mais sustentáveis.

Dentre as limitações presenciadas no decorrer deste trabalho bibliográfico, podese apontar a não utilização de outras ferramentas analíticas (softwares) que poderiam incrementar as apreciações sobre os trabalhos selecionados para o estudo, o que auxiliaria, ainda, na identificação de gaps teóricos existentes na literatura. Outra limitação que pode ser contornado em estudos futuros refere-se à ampliação do corpo textual analisado, o que proporcionaria uma visão mais apurada das incongruências identificadas na tangência do desenvolvimento sustentável nas sociedades. Contudo, de um modo geral, este trabalho conseguiu contribuir com o debate ao apontar os aspectos da mensuração do método pegada ecológica, suas vantagens e desvantagens e, principalmente, sua estreita relação com o desenvolvimento sustentável.

\section{Conflito de interesses}

Os autores declaram não haver conflito de interesses.

\section{Referências}

Andrade, B. B. Turismo e sustentabilidade no Município de Florianópolis: uma aplicação do método da pegada ecológica. Florianópolis: Universidade Federal de Santa Catarina, 2006. (Dissertação de mestrado).

Asici, A.; Acar, S. Does income growth relocate ecological footprint? Ecological Indicators, v. 61, p. 707-714, 2015. https://doi.org/10.1016/j.ecolind.2015.10.022

Bagliani, M.; Bravo, G.; S. Dalmazzone. A consumption-based approach to environmental Kuznets curves using the ecological footprint indicator. Ecological Economics, v. 65, n. 3, p. 650-661, 2008. https://doi.org/10.1016/j.ecolecon.2008.01.010

Bellen, H. M. V. Desenvolvimento sustentável: uma descrição das principais ferramentas de avaliação. Ambiente \& Sociedade, v. 7, n. 1, p. 67-87, 2004a. https://doi.org/10.1590/ S1414-753X2004000100005

Bellen, H. M. V. Indicadores de sustentabilidade: um levantamento dos principais sistemas de avaliação. Cadernos EBAPE.BR, v. 2, n. 1, p.1-14, 2004b. https://doi.org/10.1590/ S1679-39512004000100002

Bellen, H. M. V. Indicadores de sustentabilidade: uma análise comparativa. Rio de Janeiro: FGV, 2006.

Benitez, F. F.; Paredes, M. E. R.; Collado-Ruano, J.; Terán, E. F. H.; Ibarra, G. D. L. Environmental education program in Ecuador: Theory, practice, and public policies to face global change in the Anthropocene. Avaliação e Políticas Públicas em Educação, v. 27, n. 105, p. 859-880, 2019. https://doi.org/10.1590/S0104-40362019002701950 
Brundtland, G. Our common future: call for action. Environmental Conservation, v. 14, n. 4, p. 291-294, 1987. https://doi.org/10.1017/S0376892900016805

Carvalho, N. S. F. S. Desenvolvimento sustentável e políticas públicas: mensuração das pegadas hídricas e de carbono das FEAAC. Fortaleza: Universidade Federal do Ceará, 2018. (Trabalho de conclusão de curso).

Corvalan, C.; Briggs, D.; Zielhuis, G. Decision-making in environmental health: From evidence to action. Washington: WHO, 2000.

Cruz, A. A.; Fernandes, E. A. Relação PIB e meio ambiente: abordagem da pegada ecológica. Revista do Desenvolvimento Regional, v. 18, n. 1, p. 88-107, 2013.

Dias, G. F. Pegada ecológica e sustentabilidade humana. São Paulo: Global, 2015.

Galli, A.; Wiedmann, T.; Ercin, E.; Knoblauch, D.; Ewing, B.; Giljum, S. Integrating ecological, carbon and water footprint into a "Footprint Family" of indicators: Definition and role in tracking human pressure on the planet. Ecological Indicators, v. 16, p. 100-112, 2012. https://doi.org/10.1016/j.ecolind.2011.06.017

Global Footprint Network. 2011 ecological footprint and biocapacity results for all countries included in National Footprint Accounts. Oakland: Global Footprint Network, 2015.

Global Footprint Network. 2020. Disponível em: <https://www.footprintnetwork.org/>. Acesso em: 17 out. 2020.

Goes, G. A.; Morales, A. G. Gestão pública e sustentabilidade: desafios, ações e possibilidades. Periódico Eletrônico Fórum Ambiental da Alta Paulista, v. 9, n. 4, p. 199-212, 2013.

Gonzalez, M. H. G.; Andrade, D. C. A sustentabilidade ecológica do consumo em Minas Gerais: uma aplicação do método da pegada ecológica. Nova economia, v. 25, n. 2, p. 421446, 2015. https://doi.org/10.1590/0103-6351/2214

Guerra, J.; Schmidt, L. Concretizar o Wishfull Thinking: dos ODS à COP21. Ambiente \& Sociedade, v. 19, n. 4 , p. 197-214, 2016. https://doi.org/10.1590/1809-4422ASOCEx $0003 \mathrm{~V} 1942016$

Guimarães, R. P.; Feichas, S. A. Q. Desafios na construção de indicadores de sustentabilidade. Ambiente \& Sociedade, v. 12, n. 2, p. 307-323, 2009. https://doi.org/ 10.1590/S1414-753X2009000200007

Iazdi, 0.; Pedroso, F. A pegada ecológica e manutenção do capital natural: limites para o crescimento econômico? Revista Iberoamericana de Economia Ecológica, v. 32, n. 1, p. 102-119, 2020.

Macêdo, H. C.; Torres, M. F. A. Indicadores de sustentabilidade como instrumentos de planejamento e gestão socioambiental: análise do Município de Brejo da Madre de Deus PE. Revista Brasileira de Geografia Física, v. 12, n. 1, p. 81-95, 2019. https://doi.org/ 10.26848/rbgf.v12.1.p081-095

Moraes, C. S. B.; Gonçalves, J. C.; Evangelista, M. O. P.; Capparol, D. C. A. Programas e metodologias de indicadores de sustentabilidade: análise comparativa como subsídio para a gestão ambiental urbana. Brazilian Journal of Development, v. 5, n. 7, p. 10333-10366, 2019. https://doi.org/10.34117/bjdv5n7-188

Morales, A.G. A formação do profissional educador ambiental: reflexões, possibilidades e constatações. 2. ed. Ponta Grossa: UEPG, 2012. 
Nordhaus, W. D.; Tobin, J. Is growth obsolete? In: Nordhaus, W. D.; Tobin, J. Economic research: Retrospect and prospect. New York: NBER, 1972. v. 5. p. 1-80. Disponível em: <http://www.nber.org/chapters/c7620>. Acesso em: 03 mar. 2020.

Ott, W. R. Environmental indices: Theory and practice. Michigan: Ann Arbor, 1998.

Pereira, L. G. Síntese dos métodos de pegada ecológica e análise energética para diagnóstico da sustentabilidade de países: o Brasil como estudo de caso. Campinas: Universidade Estadual de Campinas, 2008. (Tese de doutorado).

Rees, W. E. Ecological footprint and appropriated carrying capacity: what urban economics leaves out. Environment and Urbanization, v. 4, p.121-130, 1992. https://doi.org/ $10.1177 / 095624789200400212$

Rodrigues, K. F.; Rippel, R. Desenvolvimento sustentável e técnicas de mensuração. Revista de Gestão Ambiental e Sustentabilidade, v. 4, n. 3. p. 73-88, 2015. https://doi.org/10.5585/geas.v4i3.387

Rohan, U.; Branco, R. R.; Sorares, C. A. P. Potencialidades e limitações dos instrumentos de mensuração da sustentabilidade. Engenharia Sanitária e Ambiental, v. 23, n. 5, p. 857869, 2018. https://doi.org/10.1590/S1413-41522018170117

Sanches, F.; Schmidt, C. Indicadores de sustentabilidade ambiental: uma análise das práticas sustentáveis em empreendimentos de turismo rural. Desenvolvimento em Questão, v. 14, n. 37, p. 89-114, 2016. https://doi.org/10.21527/2237-6453.2016.37.89114

Santos, M. F. R. F.; Xavier, L. S.; Peixoto, J. A. A. Estudo do indicador de sustentabilidade "Pegada Ecológica": uma abordagem teórico-empírica. Revistas Gerenciais, v. 7, n. 1, p. 29-37, 2008.

Siche, J. R.; Agostinho, F.; Ortega, E.; Romeiro, A. Sustainability of nations by indices: Comparative study between environmental sustainability index, ecological footprint and the emergy performance indices. Ecological Economics, v. 66, n. 4, p. 628-637, 2018. https://doi.org/10.1016/j.ecolecon.2007.10.023

Siche, R.; Agostinho, F.; Ortega, E.; Romeiro, A. Índices versus indicadores: precisões conceituais na discussão da sustentabilidade de países. Ambiente \& Sociedade, v. 10, n. 2, p. 137-148, 2007. https://doi.org/10.1590/S1414-753X2007000200009

Silva, J. F. B. A.; Rebouças, S. M. D. P.; Abreu, M. C. S.; Ribeiro, M. C. R. Construção de um índice de desenvolvimento sustentável e análise espacial das desigualdades nos municípios cearenses. Revista de Administração Pública, v. 51, n. 1. p. 149-168, 2018. https://doi.org/10.1590/0034-7612163114

United Nation. Agenda 21. Rio de Janeiro: United Nations Conference on Environment \& Development, 1992. Disponível em: <http://www.onu.org.br/rio20/img/2012/01/ agenda21.pdf>. Acesso em: 17 out. 2020.

Veiga, J. E. Indicadores de sustentabilidade. Estudos Avançados, v. 24, n. 68, p. 39-52, 2010. https://doi.org/10.1590/S0103-40142010000100006

Wackernagel, M.; Schulz, N. B.; Deumling, D.; Linares, A. C.; Jenkins, M.; Kapos, V.; Monfreda, C.; Loh, J.; Myers, N.; Norgaard, R.; Randers, J. Tracking the ecological overshoot of the human economy. Proceedings of the National Academy of Sciences of the United States of America, v. 99, n. 14, p. 9266-9271, 2002. https://doi.org/10.1073/ pnas.142033699 
Wackernagel, M.; Rees, W. Our ecological footprint: Reducing human impact on the Earth. New York: New Society Publishers, 1996.

WWW Brasil - World Wide Life Fund For Nature Brasil. A pegada ecológica de São Paulo: Estado e Capital e a família de pegada. Brasília: WWF Brasil, 2012. 